\title{
Physicochemical characterization of Sargassum polcystum C. Agardh and its activity against dinitrofluorobenzene-induced allergic contact dermatitis in mice
}

\author{
Irish Mhel C. Mitra*1, Ross D. Vasquez ${ }^{1,2,3}$ Reginald B. Salonga ${ }^{4}$, Mary Jho-Anne Corpuz ${ }^{1,2,3}$
}

\author{
${ }^{1}$ The Grad. School, Univ. of Santo Tomas, Manila, Philippines \\ ${ }^{2}$ Dep. of Pharmacy, Fac. of Pharm., Univ. of Santo Tomas, Manila, Philippines \\ ${ }^{3}$ Res. Cent. for the Natrl. and App. Sci., Univ. of Santo Tomas, Manila, Philippines \\ ${ }^{4}$ Inst. For Adv. Educ. And Res., Nagoya City University, Nagoya City, Aichi, Japan \\ *Corresponding author: irish.mhel@gmail.com
}

\begin{abstract}
Background: Sargassum polycystum C. Agardh is brown seaweed abundant in the Philippines. Recent studies showed that it has an anti-inflammatory property. However, its efficacy against allergic contact dermatitis (ACD) has not yet been studied and there are no established data regarding its physicochemical properties yet.

Objectives: The objectives of this study were to evaluate the topical efficacy of $S$. polycystum crude polysaccharide (Spcp) using dinitrofluorobenzene (DNFB)-induced ACD murine model and to conduct physicochemical characterization on Spcp.

Methods: ACD was induced by sensitizing the BALB/c mice through topical application of 0.5\% DNFB on the shaved ventral skin. Spcp $(25 \%, 12.5 \%, 6.25 \% \mathrm{w} / \mathrm{w})$ and standard drug (Betamethasone $0.10 \%$ ) were topically applied on the right ear of the mice for seven days after sensitization and right after the challenge on the eighth day. Seven days after sensitization, the right ear was challenged with $0.2 \%$ DNFB. Ear thickness was measured at baseline and 24-hrs post-challenge using a dial thickness gauge. Physicochemical characterization was also performed.

Results: The results showed that topical application of Spcp inhibited the swelling produced during 24-hrs post-challenge. The analysis revealed that the $25 \%$ Spcp exhibited a statistically significant effect and was comparable with the inhibitory effect of the standard drug, betamethasone $(\mathrm{p}<0.05)$. The physicochemical characterization showed that Spcp contains a notable amount of carbohydrates, sulfate, and protein.

Conclusion: In conclusion, our results suggest that topically applied Spcp can be an effective natural product to treat allergic contact dermatitis. However, further investigations are required to understand the mechanisms involved.
\end{abstract}

Keywords: allergic contact dermatitis, physicochemical, polysaccharide

\section{Introduction}

Allergic contact dermatitis (ACD) is a common occupational disease and environmental health issue with a tremendous socio-economic impact. ACD is among the top 5 skin diseases in terms of lost productivity. Studies found that ACD is responsible for $20-30 \%$ of all occupational diseases and $50-60 \%$ of occupational contact dermatitis (American Academy of Dermatology, 2017).

Allergic contact dermatitis is a skin inflammatory disorder caused by T-cell mediated delayed-type hypersensitivity, which negatively affects the patient's quality of life (Salonga et al., 2014). ACD results from exposure to an allergen to which the patient has already been sensitized. There are more than 85,000 chemicals in the world environment today and almost all of these substances can be an allergen (Cashman et al., 2012). In the clinical setting, topical corticosteroids are the most common treatment for ACD, but prolonged use is prohibited 
because of its known systemic adverse effects due to cumulative skin absorption (Mo et al., 2013). Therefore, there is a great need for the development of alternative treatments for ACD.

Sargassum polycystum C. Agardh, locally known as lusay-lusay or boto-boto, is a brown seaweed endemic in the Philippines. Recent studies revealed that it exhibits several pharmacological activities such as antibacterial activity (Palanisamy et al., 2019), antioxidant, anticancer activity (Palanisamy et al., 2017), and anti-HIV activity (Thuy et al., 2014). However, despite extensive studies of its pharmacological activities, none of these have focused on its topical application which offers several advantages over oral intake.

Prior to the formulation of an active compound into a dosage form, supporting scientific knowledge such as the fundamental physical and chemical properties of the active compound should be obtained. A comprehensive understanding of these properties allows the sciencebased development of the formulations. These data can be obtained by conducting physicochemical characterization (Verma \& Mishra, 2016). This study, therefore, aimed to evaluate the topical efficacy of $S$. polycystum crude polysaccharide against DNFB-induced ACD in mice and to conduct physicochemical characterization.

\section{Methods}

\subsection{Extraction of Spcp}

Fresh S. polycystum seaweed was collected from Elfarco Seaweed Farm in Calatagan, Batangas, Philippines. Samples were submitted to the University of the Philippines Marine Science Institute and identified and authenticated with the accession number MSI27992. The seaweed was washed thoroughly with distilled water, air-dried, and ground into a powder.

Spcp was extracted following the hot water extraction method by Shofia et al. (2018) with some modifications. The powdered seaweed was boiled at $100^{\circ} \mathrm{C}$ in distilled water for 3 hours and filtered with cheesecloth. The supernatant was collected after centrifugation at $4000 \mathrm{rpm}$ for 5 minutes. The crude polysaccharide was precipitated by the addition of an equal volume of absolute ethanol and was kept overnight at $4^{\circ} \mathrm{C}$. The precipitated polysaccharide was collected by centrifugation at $4000 \mathrm{rpm}$ for 5 minutes and was lyophilized to powder.

\subsection{Animals}

Healthy female BALB/c mice (6 weeks old, 20-25 grams), purchased from the Research and Biotechnology Division of St. Luke's Medical Center, Quezon City, were used in the study. The mice were housed in standard plastic cages in a temperature- and humid-controlled environment $\left(22-27^{\circ} \mathrm{C}, 60 \% \mathrm{RH}\right)$ with food and water available ad libitum. Mice were acclimatized for five days before the experimentation. All experiments were carried out following the guidelines for the care and use of experimental animals approved by the University of Santo Tomas Institutional Animal Care and Use Committee. 


\subsection{2,4-dinitrofluorobenzene-induced allergic contact dermatitis}

Allergic contact dermatitis was induced in BALB/c mice according to a published method done by Saint-Mezard et al. (2004), Salonga et al. (2014), and Yu et al. (2017). The mice were sensitized by painting their shaven abdominal skin $\left(2 \times 2 \mathrm{~cm}^{2}\right)$ with $100 \mu \mathrm{L}$ of $0.5 \%$ dinitrofluorobenzene (DNFB, Sigma-Aldrich®) in a 4:1 acetone-olive oil solution. Seven days later, the inner and outer surface of the right ear were challenged with $20 \mu \mathrm{L}$ of $0.2 \%$ DNFB in a 4:1 acetone-olive oil solution. The ear thickness was measured using a dial thickness gauge before challenge and 24-hrs after challenge. The ear swelling was calculated as the increase in ear thickness and percentage of ear swelling.

\subsection{Drug treatment}

Spcp was directly added to petrolatum, which served as the vehicle. They were mixed thoroughly in a sterile mortar. Topical treatment started right after the mice were sensitized once daily for eight days with $25 \%, 12.5 \%, 6.25 \%$, or vehicle (petrolatum). Mice were divided into seven groups with six mice per group: normal control group, negative control group, vehicle control group, positive control group, and three Spcp groups. All groups had DNFB induction except the normal control group. The negative control group did not receive any treatment, the positive control group was treated with the standard drug, betamethasone $(0.10 \%)$, the vehicle control group was treated with the petrolatum alone, and the Spcp groups were treated with ointment base containing Spcp in different concentrations $(25 \%, 12.5 \%$, $6.25 \%)$.

\subsection{Physicochemical characterization}

\subsubsection{Organoleptic analysis}

The general appearance, color, odor, and texture of the whole algae and the crude drug were described. The color was examined under diffused daylight or an artificial light source with wavelengths similar to those of daylight.

\subsubsection{Physical Characterization}

Particle size. The determination of particle size distribution of the crude drug was done through the sieving method. A 100-g crude drug was manually tapped in a stack of sieves (no. $12,20,40,60$ ) and a receiver for 30 minutes. The retained sample in each sieve was weighed.

Total ash. About 2 to 4 grams of $S$. polycystum crude drug was accurately weighed and placed in a tared crucible and incinerated at a temperature of $675 \pm 25^{\circ} \mathrm{C}$ using a furnace until being free from carbon. After cooling in a desiccator, the weight of the ash was recorded. The percentage of total ash was calculated using the formula:

$$
\% \text { Total ash }=\frac{\text { weight of total ash }}{\text { weight of sample }} \times 100
$$


Acid-insoluble ash. The ash obtained from the total ash determination was boiled with 25 $\mathrm{mL}$ of $3 \mathrm{~N} \mathrm{HCl}$ for five minutes. The insoluble matter was collected on a tared ashless filter paper and washed with hot water. After igniting the insoluble matter, the weight was recorded. The percentage of acid-insoluble ash was calculated using the formula:

$$
\% \text { Acid insoluble ash }=\frac{\text { weight of acid insoluble ash }}{\text { weight of sample }} \times 100
$$

Water-soluble ash. The ash obtained from total ash determination was boiled with $25 \mathrm{~mL}$ of water for five minutes. The insoluble matter was collected in a sintered glass crucible and washed with water. It was ignited for 15 minutes at $450^{\circ} \mathrm{C}$. Percent of water-soluble ash was computed with reference to the weight of the sample taken in the total ash determination.

$$
\% \text { Water soluble ash }=\frac{\text { weight of total ash }- \text { weight of insoluble matter }}{\text { weight of sample }} \times 100
$$

Moisture content. The moisture analyzer was set at an analysis temperature of $105^{\circ} \mathrm{C}$. An aluminum foil weighing dish with a quartz pad was placed on the balance pan. The dish and pan were allowed to dry completely to constant weight and then weighed. Ten grams of the crude drug was transferred to the quartz pad in the weighing dish. The analysis was taken as soon as the instrument balance showed a table weight. The instrument automatically shut off once the sample was dried to a constant weight. Percent moisture content was computed using the formula:

$$
\% \text { Moisture }=\frac{\text { weight }_{\text {dried sample }+ \text { dish }}-\text { weight }_{\text {dish }}}{\text { weight of sample }} \times 100
$$

pH determination. The $\mathrm{pH}$ of the crude polysaccharide was determined by immersion of the electrode of a $\mathrm{pH}$ meter at $25^{\circ} \mathrm{C}$ in a $1 \%$ aqueous solution of Spcp.

Solubility test. A supersaturated solution of the crude polysaccharide was prepared by continuously dissolving an amount of the crude polysaccharide in $5 \mathrm{~mL}$ of the solvent until it no longer dissolved. For this purpose, the following solvents were used: distilled water, 95\% ethanol, $0.1 \mathrm{~N} \mathrm{HCl}, 0.1 \mathrm{~N} \mathrm{NaOH}$, and $0.9 \% \mathrm{NaCl}$. Solutions were agitated using an Orbital Shaker for 24 hours with the bath maintained at a temperature of $37 \pm 2^{\circ} \mathrm{C}$. Solutions were filtered using a Whatman filter paper (No. 1), and $3 \mathrm{~mL}$ aliquot portion of each filtrate was transferred to tared evaporating dishes. Filtrates were evaporated to dryness for 3 hours using an oven maintained at $100^{\circ} \mathrm{C}$ to $105^{\circ} \mathrm{C}$. The residue obtained after heating was cooled in a desiccator for 30 minutes and weights were determined. The evaporating dishes with residue were similarly heated for another hour, cooled in the desiccator, and weighed. This procedure was repeated until two consecutive weighing stages did not differ more than $0.5 \mathrm{mg} / \mathrm{g}$. 


\subsubsection{Chemical analysis}

Carbohydrate content. The polysaccharide content was determined using the phenolsulfuric acid method described by Jose and Kurup (2016). In a 96-well microplate, $20 \mu \mathrm{L}$ of the sample $(1 \mathrm{mg} / \mathrm{mL})$ was pipetted in a well followed by the addition of $100 \mu \mathrm{L}$ of concentrated sulfuric acid and $20 \mu \mathrm{L}$ of $5 \%$ phenol solution. The mixture was incubated for 10 minutes at a room temperature, and absorbance was read at $490 \mathrm{~nm}$. Fucose served as the standard.

Sulfate content. The sulfate content was determined through the barium chloride-gelatin turbidity method using potassium sulfate as the standard. In a microplate, $20 \mu \mathrm{L}$ of the polysaccharide solution $(1 \mathrm{mg} / \mathrm{mL})$ was pipetted into the well followed by the addition of 190 $\mu \mathrm{L}$ of $0.5 \mathrm{M}$ hydrochloric acid and $50 \mu \mathrm{L} \mathrm{BaCl}$-gelatin solution. The mixture was incubated for 20 minutes at a room temperature, and absorbance was read at $360 \mathrm{~nm}$ (Jose \& Kurup, 2016).

Protein content. Protein content was measured using the Bradford assay described by Jose \& Kurup (2016). Three microliters of polysaccharide solution $(1 \mathrm{mg} / \mathrm{mL})$ was pipetted into a 96-well microplate. To each well, $150 \mu \mathrm{L}$ of the Bradford reagent was added. The mixture was incubated for 5 minutes at a room temperature, and the absorbance was read at $595 \mathrm{~nm}$. Bovine serum albumin served as the standard.

Uronic acid content. The uronic acid content of the crude polysaccharide was determined by the carbazole method using galacturonic acid as the standard. The crude polysaccharide (1 $\mathrm{mg} / \mathrm{mL}$ ) was heated in a boiling water bath for 10 minutes with $0.025 \mathrm{M}$ sodium carbonate. Then $0.1 \%$ carbazole in methanol solution was added and boiled continuously for 15 minutes. The absorbance was read at $540 \mathrm{~nm}$ (Jose \& Kurup, 2016).

\subsection{Statistical analysis}

Results were expressed as mean \pm SEM of three independent measurements. Statistical analysis was conducted by ANOVA and Tukey's tests. P values of less than 0.05 were considered statistically significant.

\section{Results and discussion}

\subsection{Extraction of the crude polysaccharide}

Sargassum polycystum (Fig. 1a) was air-dried and ground into a powder to extract crude polysaccharide using the hot water extraction method. The extract was lyophilized to powder (Figure 1) to prevent further degradation. A total yield of $4.17 \%$ of crude polysaccharide was extracted from the dried material. The yield of crude polysaccharide was comparable to previous studies (Nagappan et al., 2017; Palanisamy et al., 2018). The lyophilized sample appeared as brownish powder with a distinct saltwater odor. 


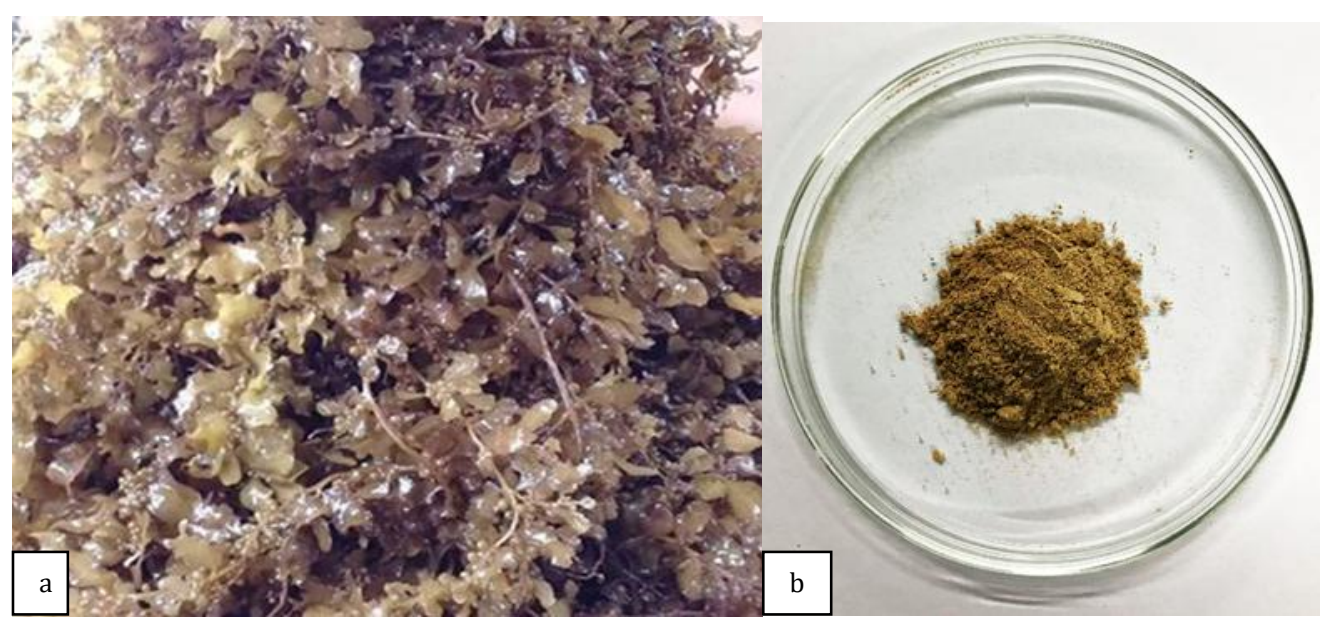

Figure 1. a. Fresh Sargassum polycystum; b. Sargassum polycystum crude polysaccharide lyophilized powder

\subsection{Inhibition of DNFB-induced allergic contact dermatitis}

Allergic contact dermatitis, a common clinical skin disease, is a delayed-type hypersensitivity. It is a T-cell mediated inflammatory reaction that occurs at the site of contact with the allergen; it is commonly characterized by redness, papules, and vesicles, which later develops scaling and dry skin. The most common allergens are metals, cosmetic and skincare products, fragrances, and topical antibiotics (Saint-Mezard et al., 2004).

The mouse ear swelling test seeks to identify potential contact allergens based on challenge-induced increases in ear thickness in sensitized animals. Spcp (25\%, 12.5\%, 6.25\%) was topically applied once daily for eight days on mice to evaluate the effect of Spcp on ACD. The establishment of the DNFB-induced allergic contact dermatitis murine model and the dosage regimen are illustrated in Figure 2. Based on the average ear swelling 24-hrs post-challenge (Figure 3) and percent increase in ear thickness 24-hrs post-challenge (Figure 4), topical application of Spcp could inhibit DNFB-induced allergic contact dermatitis. The analysis reveals that all the concentrations were statistically able to decrease the ear swelling compared to the untreated group. Also, the effect of $25 \%$ Spcp was comparable to the inhibitory effect of the standard drug, betamethasone. The above mentioned results imply that the topical application of Spcp could significantly suppress the inflammatory responses in DNFB-induced allergic contact dermatitis. 


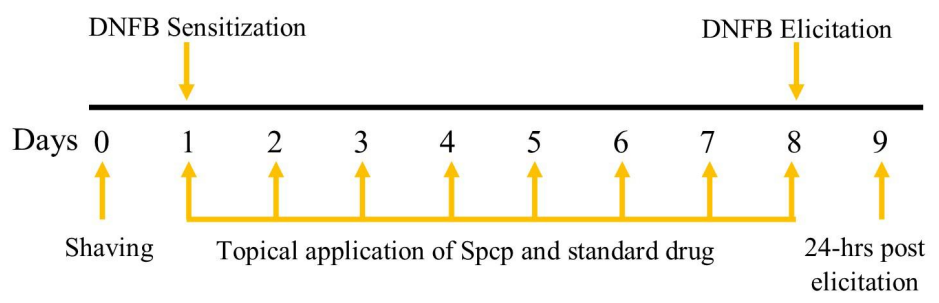

Figure 2. DNFB-induced allergic contact dermatitis murine model and dosing regimen

Figure 2. DNFB-induced allergic contact dermatitis murine model and dosage regimen

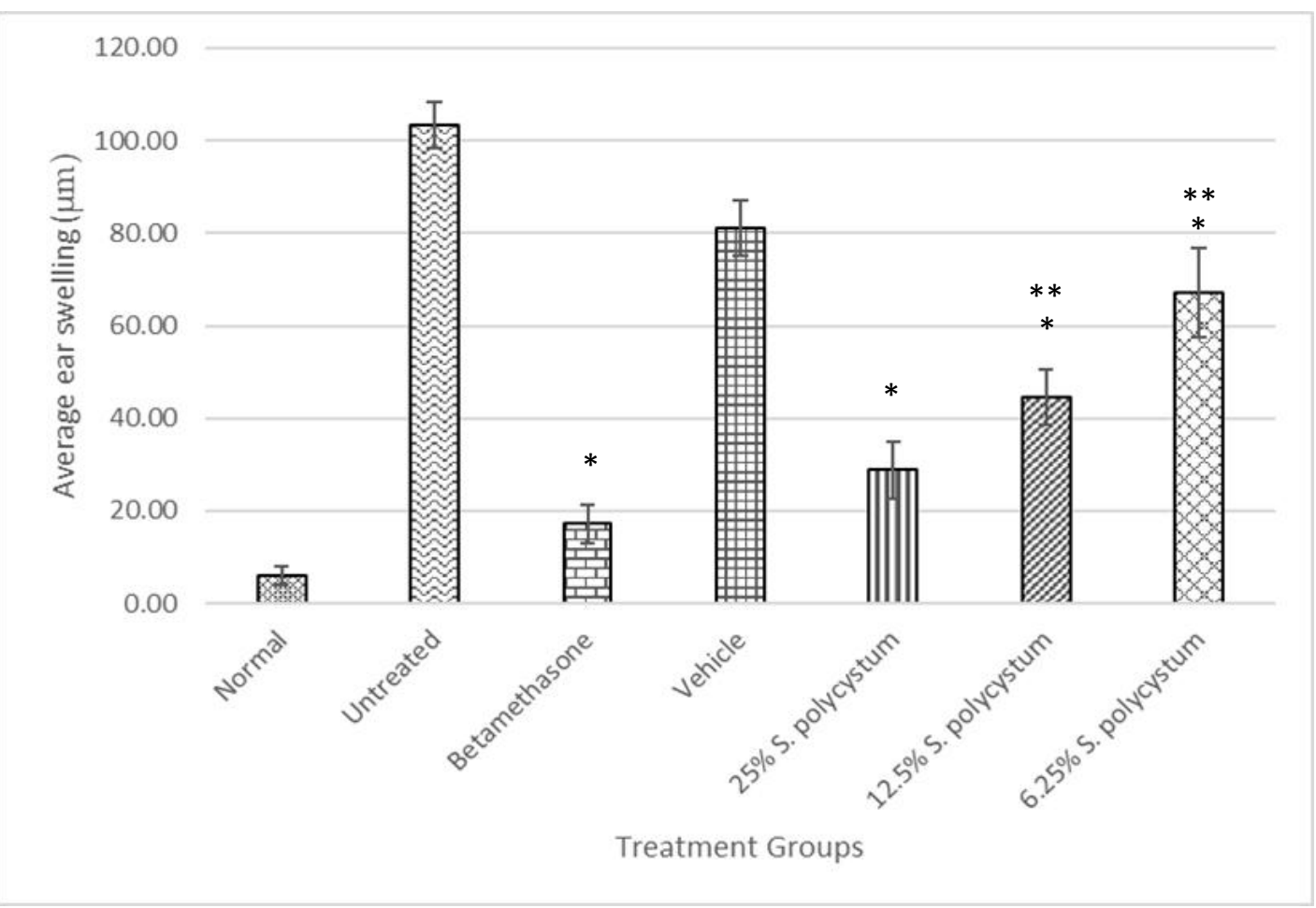

Figure 3. Average ear swelling 24-hrs post-challenge Values are expressed as mean \pm SEM of 6 mice.

*Denotes a significant difference against untreated group.

**Denotes a significant difference against the group treated with the standard drug, betamethasone. $(\mathrm{p}<0.05)$ by ANOVA and Tukey's tests. 


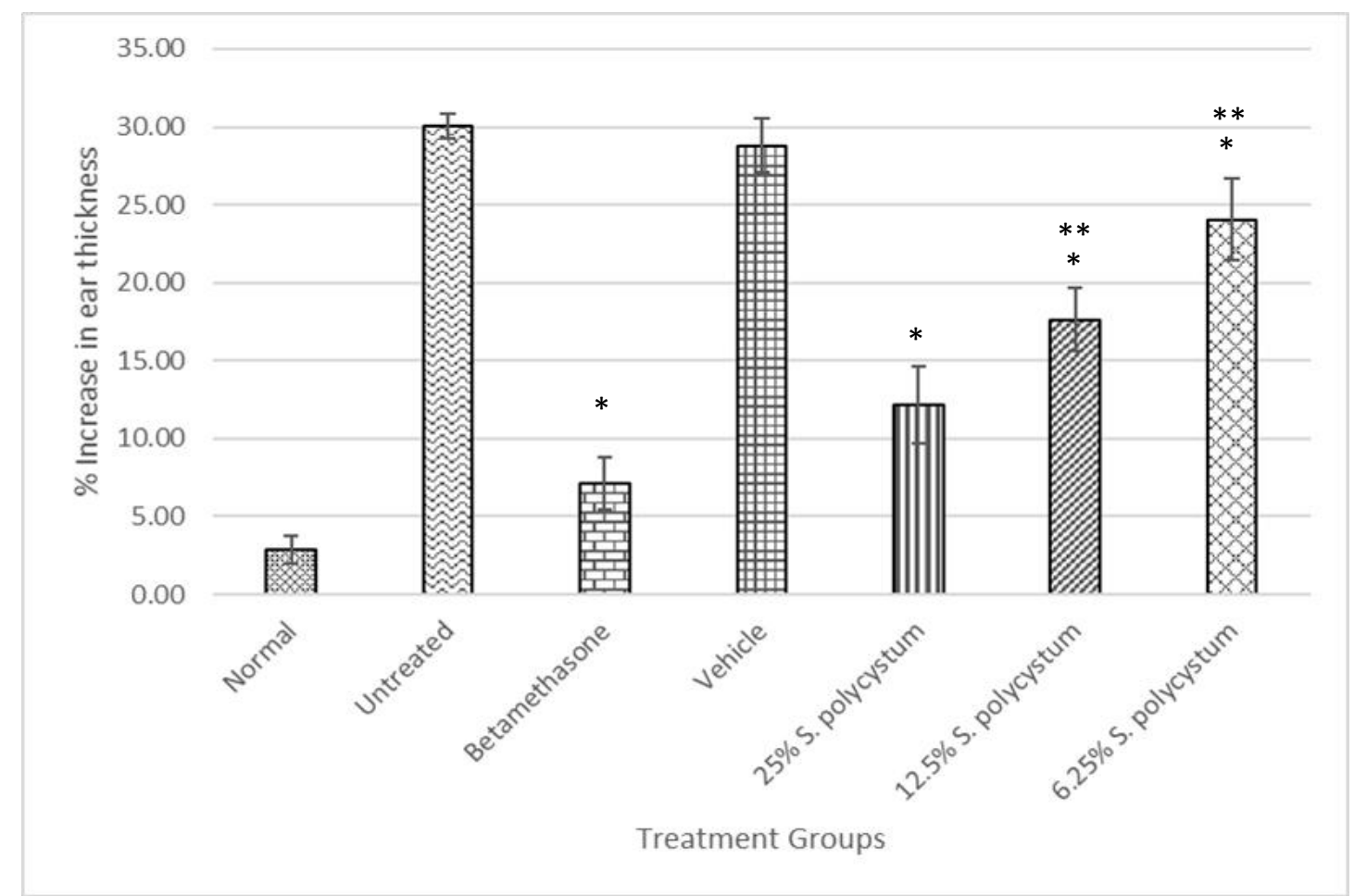

Figure 4. Percent increase in ear thickness 24-hrs post-challenge Values are expressed as mean \pm SEM of 6 mice.

*Denotes a significant difference against untreated group.

**Denotes a significant difference against the group treated with the standard drug, betamethasone. $(\mathrm{p}<0.05)$ by ANOVA and Tukey's tests.

\subsection{Physicochemical characterization}

To guarantee the reproducible quality of herbal medicines, proper characterization of the starting material is essential. One determinant towards ensuring the quality of starting material is establishing numerical values of standards for a comparison. In this study, the researchers aimed to characterize the physicochemical properties of Spcp which are essential to determine the possible bioactive constituent responsible for the inhibitory activity against ACD. Also, the physicochemical parameters are essential to determine the suitability of the sample to be developed into a formulated dosage form.

\subsection{Organoleptic analysis}

The primary step in ensuring a quality herbal plant is authentication. In the present study, the researchers aimed to provide data that will be of great importance in establishing standard parameters that may be used in the authentication and standardization of S. polycystum.

The thallus of $S$. polycystum is yellowish-brown, up to $90 \mathrm{~cm}$ tall, and holdfast a plate-like alga up to about $7 \mathrm{~mm}$ in diameter. The stem is brownish and finely villose, short, and usually about $10 \mathrm{~mm}$ long. The primary branch is highly compressed at the distal end of the stem, terete, and lumpy with elevated cryptostomata. Leaves on the main branches of vegetative materials are generally larger, broadly lanceolate, base asymmetrical, margin finely but irregularly serrate-dentate, and midrib distinct almost to apex of leaves. Cryptostomata are numerous, 
distinct and elevated, and scattered on leaves and vesicles. Vesicles are numerous, very small about 1.5-2.5 mm long and 1.0-2.0 $\mathrm{mm}$ wide, and mainly spherical-ovate to slightly elliptical (Trono, 1992).

The histologic features of fresh S. polycystum stipe (Figure 5) and blade (Figure 6) were also observed. The cells in the stipe are differentiated into epidermis that contains chromatophores which are responsible for photosynthesis, cortex which is made up of parenchymatous cells and serves as the storage tissue, and medulla. On the other hand, the cells in the blade are differentiated into epidermis and mesophyll tissue. Mesophyll tissue is made up of parenchymatous cells where pigments are located.

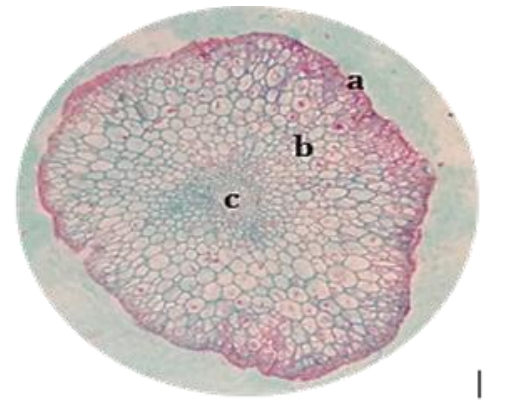

Figure 5. Histologic features of S.polycystum stipe blade (a)epidermis; (b) cortex; (c) medulla

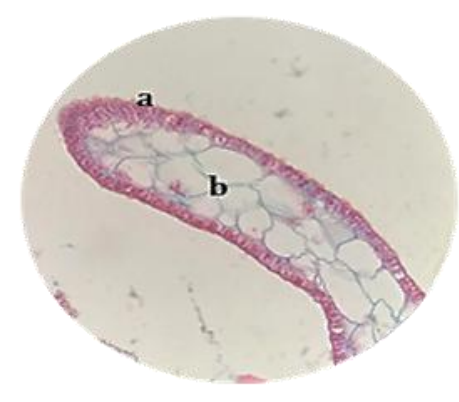

Figure 6. Histologic features of $S$. polycystum (a) epidermis; (b) mesophyll tissue

Physical characteristics. Physical characterization of an herbal plant is a basic protocol for the standardization of herbal medicines. Table 1 shows the physical characteristics of Spcp. The total ash value is essential in the identification and authentication of the sample and to examine adulterants from the original species of biological importance. Establishing the $\mathrm{pH}$ and solubility of the sample provides useful data about the nature of the sample. These collective physicochemical properties are essential to determine the suitability of the sample to be developed into a formulated dosage form.

Table 1. Physical characteristics of Spcp

\begin{tabular}{lc}
\hline Parameters & Value \\
\hline Particle size & 425 microns -820 microns \\
Total ash content & $23.76 \%$ \\
Acid-insoluble ash & $0.46 \%$ \\
Water-soluble ash & $11.78 \%$ \\
Moisture content & $12.90 \%$ \\
pH & 7.40 \\
Solubility & \\
Distilled Water & \\
O.9\% NaCl & Slightly soluble \\
Ethanol & Sparingly soluble \\
HCl & Very slightly soluble \\
$\mathrm{NaOH}$ & Sparingly soluble \\
\hline
\end{tabular}


Chemical composition. The chemical analysis indicates that Spcp (Table 2) is composed primarily of carbohydrates (33.60\%) and exhibits high sulfate content (23.66\%), a notable amount of protein $(7.46 \%)$, and a small amount of uronic acid (1.50\%). Sulfated polysaccharide present in seaweed is composed of carbohydrate backbone with ester sulfate substitution in the sugar residue. Recent investigations showed that the biological activities of marine algae might be attributed to its sulfated polysaccharide content (Guerra Dore et al., 2013; Raghavendran et al., 2005).

Table 2. Chemical composition of Spcp

\begin{tabular}{lc}
\hline Parameters & Percentage (\%)* \\
\hline Carbohydrate & $33.603 \pm 0.371 \%$ \\
Sulfate & $23.656 \pm 0.124 \%$ \\
Protein & $7.456 \pm 0.348 \%$ \\
Uronic acid & $1.501 \pm 0.011 \%$ \\
\hline *Values are expressed as mean (N=9) \pm SEM.
\end{tabular}

Several studies have been done to evaluate the anti-inflammatory activity of Sargassum crude sulfated polysaccharide. Neelakandaan et al. (2016), evaluated S. wightii sulfated polysaccharide for its in vivo anti-inflammatory effect using carrageenan-induced rat paw edema. Results showed that $S$. wightii sulfated polysaccharide significantly reduced the paw edema in a dose-dependent manner. In a study conducted by Fernando et al., (2018), crude sulfated polysaccharide from $S$. polycystum showed a strong anti-inflammatory activity when tested against lipopolysaccharide (LPS)-stimulated RAW 264.7 macrophages. Decreased production of NO, PGE 2 , TNF- $\alpha$, IL-1 $\beta$ and IL- 6 was also observed. In a following study, Fernando et al., (2018) found that $S$. polycystum crude polysaccharide was rich in fucoidan with high sulfate content of $27.53 \pm 0.55 \%$. The observed activity of Spcp from S. polycystum is attributed to its high sulfate content which is found comparable to and in good agreement with the sulfate content of other Sargassum species. For instance, S. vulgare and S. tenerrimum were reported to contain 22.6\% and 22.14\%, respectively (Guerra Dore et al., 2013; Mohan et al., 2019). Both types of seaweed were reported to have a strong antioxidant activity. Sanjeewa et al (2017) reported that the sulfated polysaccharide from $S$. horneri had the same IR spectra as a commercial fucoidan. Fucoidan is a dominant sulfated polysaccharide found in brown seaweed (Saraswati, 2019). Fucoidan from marine macroalgae has been studied for its anti-allergic activity. Yang (2012) and Tian et al. (2019) reported that fucoidan from brown seaweed is as effective as dexamethasone in improving atopic dermatitis symptoms. 


\section{Conclusion}

In conclusion, the crude polysaccharide from $S$. polycystum can be an effective natural product to treat allergic contact dermatitis. However, further investigations are required to understand the mechanisms involved. Also, the physicochemical properties of Sargassum polycystum crude polysaccharide revealed through this study can be a basis for future research in developing a formulation of dosage form.

\section{Acknowledgment}

This work was supported by financial grants from the National Research Council of the Philippines (NRCP) with the project code: 0-016 and the Department of Science and Technology - Accelerated Science and Technology Human Resource Development Program (DOST-ASTHRDP).

\section{References}

American Academy of Dermatology. (2017). Contact Dermatitis by the Numbers. Skin Disease Briefs.

Cashman, M.W., Reutemann, P.A., \& Ehrlich, A. (2012). Contact Dermatitis in the United States: Epidemiology, Economic Impact, and Workplace Prevention. Dermatologic Clinics, 30, 87-98.

Fernando, I. P. S., Sanjeewa, K. K. A., Samarakoon, K. W., Kim, H. S., Gunasekara, U. K. D., Park, Y. J., Abeytunga, D. T. U. et al. (2018). The potential of fucoidans from Chnoospora minima and Sargassum polycystum in cosmetics: antioxidant, anti-inflammatory, skin-whitening, and antiwrinkle activities. Journal of Applied Phycology, 30, 3223-3232.

Fernando, I. P. S., Sanjeewa, K. K. A., \& Samarakoon, K. W. (2018). Antioxidant and antiinflammatory functionality of ten Sri Lankan seaweed extracts obtained by carbohydrase assisted extraction. Food Science and Biotechnology, 27, 1761-1769.

Guerra Dore, C. M. P., Faustino Alves, M. G. C., Pofirio Will, L. S. E., Costa, T. G., Sabry, D. A., \& de Souza Rego, L. A. R. (2013). A sulfated polysaccharide, fucans, isolated from brown algae Sargassum vulgare with anticoagulant, antithrombotic, antioxidant and antiinflammatory effects. Carbohydrate Polymers, 91, 467-475.

Jose, G.M.J. \& Kurup, M. (2016). In vitro antioxidant properties of edible marine algae Sargassum swartzii, Ulva fasciata and Chaetomorpha antennina of Kerala coast. Pharmaceutical Bioprocessing (4) 5, 100-108.

Mo, J., Panichayupakaranant, P., Kaewnopparat, N., Nitiruangjaras, A., \& Reanmongkol, W. (2013). Topical anti-inflammatory and analgesic activities of standardized pomegranate rind extract in comparison with its marker compound ellagic acid in vivo. Journal of Ethnopharmacology, 148, 901-908.

Mohan, M. S. G., Achary, A., Mani, V., Cicinskas, E., Kalitnik, A. A., \& Khotimchenko, M. (2019). Purification and characterization of fucose-containing sulphated polysaccharides from Sargassum tenerrimum and their biological activity. Journal of Applied Phycology.

Nagappan, H., Pee, P. P., Kee, S. H. Y., Ow, J. T., Yan, S. W., Chew, L. Y. et al. (2017). Malaysian brown seaweeds Sargassum siliquosum and Sargassum polycystum: Low-density lipoprotein (LDL) oxidation, angiotensin-converting enzyme (ACE), $\alpha$-amylase, and $\alpha$ glucosidase inhibition activities. Food Research International, 99, 950-958.

Neelakandan, Y. \& Venkatesan, A. (2016). Antinociceptive and anti-inflammatory effect of sulfated polysaccharide gractions from Sargassum wightii and Halophila ovalis in male Wistar rats. Indian Journal of Pharmacology, 48(5), 562-570. 
Palanisamy, S., Vinosha, M., Marudhupandi, T., Rajasekar, P., \& Prabhu, N. (2017). Isolation of fucoidan from Sargassum polycystum brown algae: Structural characterization, in vitro antioxidant and anticancer activity. International Journal of Biological Macromolecules, $102,405-412$.

Palanisamy, S., Vinosha, M., Manikandakrishnan, M., Anjali, R., Rajasekar, P., Marudhupandi, T, et al. (2018). Investigation of antioxidant and anticancer potential of fucoidan from Sargassum polycystum. International Journal of Biological Macromolecules, 116, 151-161.

Palanisamy, S., Vinosha, M., Rajasekar, P., Anjali, R., Sathiyaraj, G., Marudhupandi, T., et al. (2019). Antibacterial efficacy of a fucoidan fraction (Fu-F2) extracted from Sargassum polycystum. International Journal of Biological Macromolecules, 125, 485-495.

Raghavendran, H. R. B., Sathivel, A. \& Devaki, T. (2005). Antioxidant effect of Sargassum polycystum (Phaeophyceae) against acetaminophen-induced changes in hepatic mitochondrial enzymes during toxic hepatitis. Chemosphere, 61, 276-281.

Saint-Mezard, P., Rosieres, A., Krasteva, M., Berard, F., Dubois, B., Kaiserlian, D., et al. (2004). Allergic Contact Dermatitis. European Journal of Dermatology, 14, 284-295.

Salonga, R.B., Hisaka, S., \& Nose, M. (2014). Effect of the hot water extract of Artocarpus camansi leaves on 2,4,6-Trinitrochlorobenzene (TNCB)-induced contact hypersensitivity in mice. Biological and Pharmaceutical Bulletin, 37 (3), 493-497.

Sanjeewa, K. K. A., Fernando, I. P. S., Kim, E.A., Ahn, G., Jee, Y. \& Jeon,Y. J. (2017). Antiinflammatory activity of a sulfated polysaccharide isolated from an enzymatic digest of brown seaweed Sargassum horneri in RAW 264.7 cells. Nutrition Research and Practice, $11(1), 3-10$.

Saraswati, Giriwono, P. E., Iskandriati, D., Tan, C. P. \& Andarwulan, N. (2019). Sargassum seaweed as a source of anti-inflammatory substances and the potential insight of the tropical species: A review. Marine Drugs, 17, 590.

Shofia, S. I., Jayakumar, K., Mukherjee, A., \& Chandrasekaran, N. (2018). Efficiency of brown seaweed (Sargassum longifolium) polysaccharides encapsulated in nanoemulsion and nanostructured lipid carrier against colon cancer cell lines HCT 116. Royal Society of Chemistry, 8, 15973-15984.

Thuy, T., Ly, B. M., Van, T., Quang, N. V., Tu, H. C., Zheng, Y. et al. (2014). Anti-HIV activity of fucoidans from three brown seaweeds species. Carbohydrate Polymers, 115, 122-128.

Tian, T., Chang, H., He, K., Ni, Y., Li, C., Hou, M., et al. (2019). Fucoidan from seaweed Fucus vesiculosus inhibits 2,4-dinitrochlorobenzene-induced atopic dermatitis. International Immunopharmacology, 75.

Trono, G.C. (1992). The genus Sargassum in the Philippines. Conference: Taxonomy of Economic Seaweeds with reference to some Pacific and Carribean species.

Verma, G. \& Mishra, M.K. (2016). Pharmaceutical Preformulation Studies in Formulation and Development of Dosage Form: A Review. International Journal of Pharma Research \& Review, 5 (10), 12-20.

Yang, J.H. (2012). Topical application of fucoidan improves atopic dermatitis symptoms in Nc/Nga mice. Phytotherapy Research, 26, 1898-1903.

Yu. J., Wan, K. \& Sun, X. (2017). Improved transdermal delivery of morin efficiently inhibits allergic contact dermatitis. International Journal of Pharmaceutics, 530, 145-154. 